\title{
GUT Dysbiosis in inflammatory bowel disease: a role for bacteriophages?
}

P Lepage, J Colombet, P Marteau, T Sime-Ngando, J Doré and M Leclerc

Gut 2008:57:424-425

doi:10.1136/gut.2007.134668

Updated information and services can be found at:

http://gut.bmj.com/cgi/content/full/57/3/424

\section{These include:}

References This article cites 3 articles, 1 of which can be accessed free at: http://gut.bmj.com/cgi/content/full/57/3/424\#BIBL

Email alerting Receive free email alerts when new articles cite this article - sign up in the box at service the top right corner of the article

Notes

To order reprints of this article go to:

http://journals.bmj.com/cgi/reprintform

To subscribe to Gut go to:

http://journals.bmj.com/subscriptions/ 


\section{LETTERS}

\section{Dysbiosis in inflammatory bowel disease: a role for bacteriophages?}

Intestinal bacteria have been implicated in the initiation and amplification of inflammatory bowel disease (IBD). The dysbiosis theory, reviewed by Tamboli et al (Gut 2004;53:1), is that an imbalance between putative "harmful" versus "protective" bacterial species may promote chronic intestinal inflammation. Although several studies published so far support this hypothesis, the most vexing question posed by Tamboli et al remains "what is the origin of dysbiosis?". Bacteriophages outnumber bacteria by a factor of 10 in many natural ecosystems, exert a strong influence on bacterial diversity and population structure, and are probably involved in dysbiosis by destabilising bacterial communities. ${ }^{1}$ They could be involved indirectly through gene transfer and genome reorganisation within the bacterial population or directly as immunomodulating agents ${ }^{2}$ or by steric competition for microbe-associated molecular patterns on bacterial surfaces. However, bacteriophages are a neglected component of the gut microbiota. The first viral metagenomic study demonstrated a wide diversity (1200 genotypes) of uncultured bacteriophage species. ${ }^{3}$ The present study aimed at measuring the total viral community associated with the gut mucosa and comparing viral abundance between healthy individuals and patients with Crohn's disease (CD), and also between the ulcerated and non-ulcerated mucosa of these patients.

Fourteen healthy individuals and 19 CD patients were recruited and gave their informed consent. Biopsies were obtained
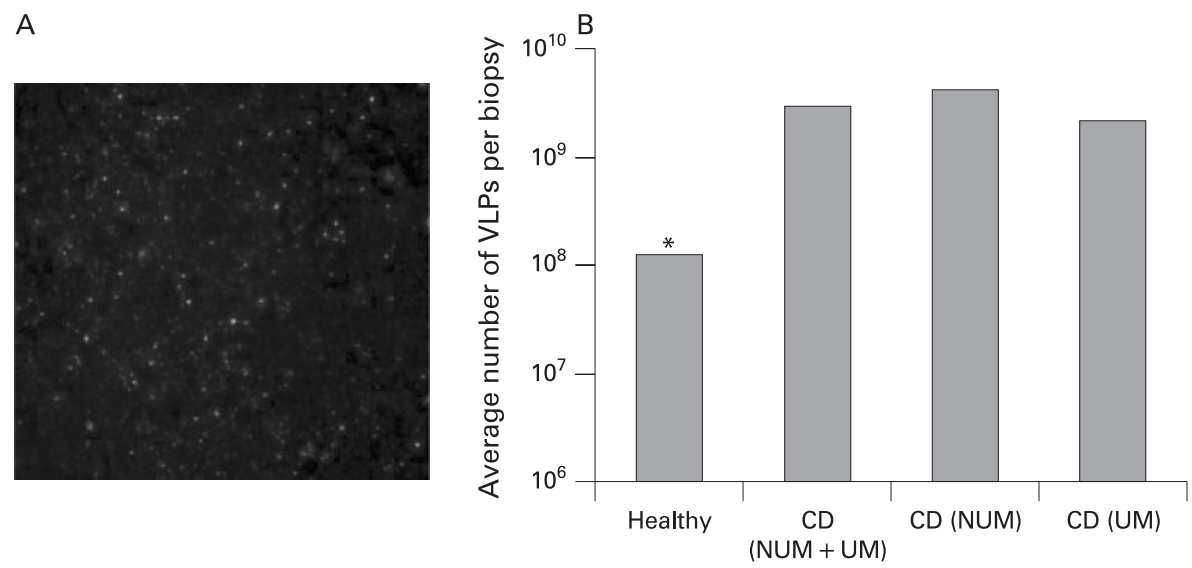

Figure 1 Concentrations of virus-like particles (VLPs) assessed by epifluorescence microscopy on gut mucosal samples from healthy individuals and Crohn's disease (CD) patients. (A) SYBR Green Istained human mucosal viral concentrate from a healthy individual (concentrate diluted to $5 \times 10^{-4}$ ). (B) Average number of VLPs per biopsy in the different clinical groups. ${ }^{*} p=0.024$ Wilcoxon text. NUM, non-ulcerated mucosa; UM, ulcerated mucosa. during colonoscopy and, for CD patients, from non-ulcerated and ulcerated tissues. Biopsies were disrupted by ultrasonication, filtered through $0.22 \mu \mathrm{m}$ membranes and fixed in glutaraldehyde. For epifluorescence microscopy, biopsy supernatants were filtered through $0.02 \mu \mathrm{m}$ membranes. Viruslike particles (VLPs) were stained with SYBR Green and counted on triplicate subsamples. VLPs were detected in every sample, and no contaminating bacteria were observed (fig 1A). Strikingly high numbers of VLPs were observed (fig 1B), with an average of 1 . $2 \times 10^{9} \quad$ VLPs/biopsy $\left(4.4 \times 10^{7}-1.7 \times 10^{10}\right)$. Transmission electron microscopy demonstrated that viral particles corresponded to bacteriophages, with morphotypes consistent with Siphoviridae, Myoviridae and Podoviridae being the dominant families (fig 2). Each individual seemed to be colonised by one dominant phage family. This result was confirmed by pulse-field gel electrophoresis of viral genomic DNA (data not shown). At the mucosal level and with specific reference to the potential role of bacteriophages in dysbiosis, CD patients harboured significantly more VLPs than healthy individuals $\left(2.9 \times 10^{9}\right.$ vs $1.2 \times 10^{8}$ VLPs/biopsy; Wilcoxon test $p=0.024$ ). Moreover, decreased amounts of VLPs were detected in CD ulcerated mucosa, with an average of $2.1 \times 10^{9} \mathrm{VLP} /$ biopsy compared with $4.1 \times 10^{9} \mathrm{VLP} /$ biopsy from non-ulcerated mucosa (fig 1). It can be hypothesised either that more viruses are produced or that they can survive longer in non-ulcerated areas. Whether bacterial composition and abundance differ when comparing nonulcerated with ulcerated mucosa is still controversial although differing bacteriophage life cycles (lysis, lysogeny) could be responsible for some of these discrepancies.

This study shows for the first time a dense bacteriophage community specifically associated with the gut mucosa, reaching $10^{10}$ / $\mathrm{mm}^{3}$ of tissue. Significantly more bacterio-
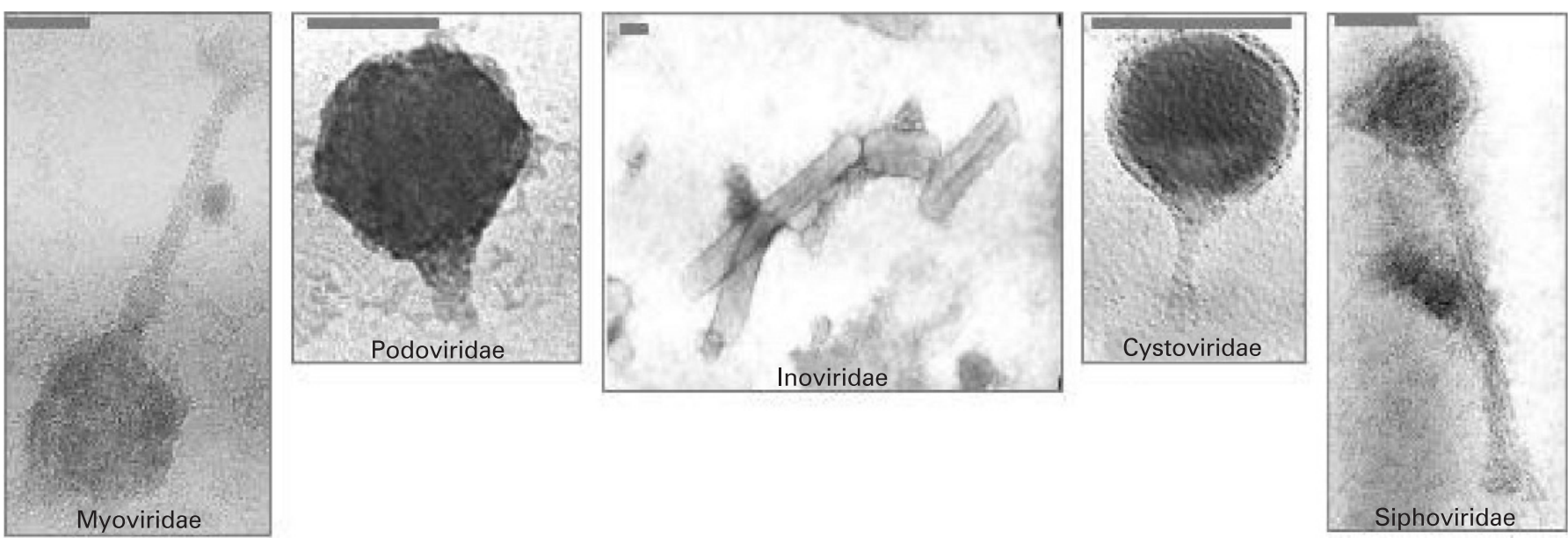

Figure 2 Transmission electron microscopy observation (80 kV, $\times 40000$ magnification) of bacteriophage morphotypes from mucosal samples. The dominant morphotypes are Myoviridae, Podoviridae and Siphoviridae. The grey bar represents $100 \mathrm{~nm}$. 
phages were detected in the mucosa from $\mathrm{CD}$ patients than from healthy individuals. Tamboli et al discussed risk factors known to affect the gut microbial composition (host genetic background, method of birth delivery, early bacterial colonisation of neonates, diet and environment) which could be responsible for dysbiosis. Based on our results, we postulate that bacteriophages might also play a key role in the dysregulated immune response of IBD patients to the mucosal-associated bacterial population. More detailed studies that relate phage populations to disturbances in bacterial populations and the dysregulated host immune response on larger cohorts would help in establishing their role in the pathogenesis of IBD.

\section{P Lepage, ${ }^{1} \mathrm{~J}$ Colombet, ${ }^{2}$ P Marteau, ${ }^{3}$ T Sime-Ngando, ${ }^{2}$ J Doré,' M Leclerc ${ }^{1}$}

1 Unité d'Ecologie et de Physiologie du Système Digestif, INRA, Domaine de Vilvert, Jouy en Josas cedex, France; ${ }^{2}$ Laboratoire de Biologie des Protistes, UMR CNRS 6023, Université Blaise Pascal, Aubière cedex, France; ${ }^{3} \mathrm{AP}-\mathrm{HP}$, Hôpital Lariboisière, 2 rue A. Paré, Paris, France

Correspondence to: Dr M Leclerc, Unité d'Ecologie et de Physiologie du Sytème Digestif, INRA, Bat 405, Domaine de Vilvert 78350 Jouy en Josas, France; marion.leclerc@jouy. inra.fr

Competing interests: None.

Gut 2008;57:424-425. doi:10.1136/gut.2007.134668

\section{REFERENCES}

1. Riley PA. Bacteriophages in autoimmune disease and other inflammatory conditions. Med Hypotheses 2004;62:493-8.

2. Gorski A, Kniotek M, Perkowska-Ptasinska A, et al. Bacteriophages and transplantation tolerance. Transplant Proc 2006;38:331-4.

3. Breitbart M, Hewson I, Felts B, et al. Metagenomic analyses of an uncultured viral community from human feces. J Bacteriol 2003;185:6220-3.

\section{Disseminated tuberculosis in a Crohn's disease patient on anti- TNF $\alpha$ therapy despite chemoprophylaxis}

We read with interest the article by Rampton et al (Gut 2005;54:1360) concerning the prevention of tuberculosis (TB) in patients with Crohn's disease (CD) needing treatment with anti-tumour necrosis factor $\alpha(\mathrm{TNF} \alpha)$ agents. Opportunistic infections and particularly $\mathrm{TB}$ are of major concern among patients who are candidates for treatment with such cytokine inhibitors. Although in rheumatoid arthritis large prospective studies reveal an increased risk for TB activation despite appropriate chemoprophylaxis, ${ }^{12}$ there is no similar study in $\mathrm{CD}$ patients. We present the case of a $\mathrm{CD}$ patient on therapy with infliximab who presented with signs and symptoms of disseminated TB. To the best of our knowledge, this is the first report of disseminated $\mathrm{TB}$ in a patient with $\mathrm{CD}$ who had already received proper chemoprophylaxis prior to anti-TNF $\alpha$ treatment.
A 42-year-old Greek man was admitted to our department because of high fever up to $40^{\circ} \mathrm{C}$ of 10 days duration, weight loss $(6 \mathrm{~kg}$ in the last month), dry cough and headache. His medical history was significant for inflammatory ileocolonic CD with articular involvement of 13 years duration. The patient experienced clinical remission on therapy with infliximab $(5 \mathrm{mg} / \mathrm{kg})$ every 8 weeks and azathioprine ( $2 \mathrm{mg} / \mathrm{kg}$ ) for the last 3 years. Due to a positive PPD (purified protein derivative) test, he received, with good compliance, isoniazid (INH) for 2 months prior to commencement of antiTNF $\alpha$ therapy and for a total of 6.5 months. For the last 2 years he was under close clinical and radiological surveillance (chest and abdominal CT) because of persistent lymphadenopathy (axillary, mediastinal and lower mesenteric) which was attributed to generalised Bartonellosis after a thorough work-up that included lymph node and bone marrow biopsies. He had no signs of infection on his previous infliximab infusion 1 month prior to this admission.

The physical examination revealed crackles of the medial and basal areas of the right lung. Laboratory tests were significant for leucocytosis (white blood cells $(\mathrm{WBC})=16.200)$, elevated erythrocyte sedimentation rate $(\mathrm{ESR} ; 101 \mathrm{~mm} / \mathrm{h})$ and C- reactive protein $(12 \mathrm{mg} / \mathrm{dl}$; normal $<0$. 8). CT scanning revealed diffused micronodular lesions in both lungs with a miliary pattern, and expansion of the pre-existent lymphadenopathy to the upper mesenterium. MRI of the head revealed a $4 \mathrm{~mm}$ lesion of the left occipitoparietal region without signs of abscess. Bronchoscopically obtained lung biopsies and sputum stains were not diagnostic and thus he underwent thoracoscopy. Empiric levofloxacin treatment $(750 \mathrm{mg}$ /day for 15 days) resulted in fever remission with a relapse 6 days after treatment discontinuation. Biopsies taken from the right lung confirmed the diagnosis of active tuberculosis (fig 1). Interestingly, cultures for TB in blood, bronchoalveolar lavage and sputum were negative. Therapy with rifampin, INH, pyrazinamide and ethambutol resulted in an impressive clin-

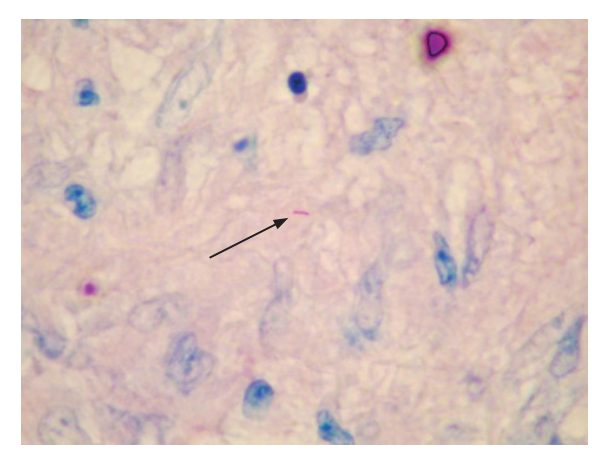

Figure 1 Ziehl-Neelsen stain of a lung tissue section reveals an acid-fast bacillus (arrow; magnification $\times 100$ ). ical and radiological improvement during the first month of treatment.

This is the first report of disseminated TB (chest, abdomen and brain) in a CD patient on anti-TNF $\alpha$ treatment despite chemoprophylaxis with INH. We think that it was a reactivation of latent $T B$ rather than a new infection. Looking at the case retrospectively, it seems that the diagnosis of Bartonellosis (based merely on serological evidence) was actually missed TB. According to Rampton's algorithm and current guidelines, 6-9 months of INH chemoprophylaxis has been proposed for patients with latent TB with an indication for anti-TNF $\alpha$ treatment. Our case indicates that in CD patients on anti-TNF $\alpha$ treatment appropriate INH prophylaxis does not eliminate the risk for TB activation, and a close follow-up for TB activation is required. Therapy with quinolones, a common empiric treatment in CD flares, may delay the diagnosis of $\mathrm{TB}$ because of their well-known anti-TB activity. ${ }^{3}$ Our case outlines the need of continuous reassessment of our practice in preventing latent $\mathrm{TB}$ reactivation in patients on antiTNF $\alpha$ agents.

\section{A Bourikas, ${ }^{1}$ I S Kourbeti, ${ }^{2}$ A V Koutsopoulos, ${ }^{3}$ \\ I E Koutroubakis ${ }^{1}$}

${ }^{1}$ Department of Gastroenterology, University Hospital of Heraklion, Crete, Greece; ${ }^{2}$ Department of Medicine, University, Hospital of Heraklion, Crete, Greece;

${ }^{3}$ Department of Pathology, University Hospital of Heraklion, Crete, Greece

Correspondence to: Professor I E Koutroubakis, Department of Gastroenterology, University Hospital of Heraklion, PO Box 1352, 71110 Heraklion, Crete, Greece; ikoutroub@med.uoc.gr

Gut 2008;57:425. doi:10.1136/gut.2007.132407

\section{REFERENCES}

1. Gomez-Reino JJ, Carmona L, Angel Descalzo M: Biobadaser Group. Risk of tuberculosis in patients treated with tumor necrosis factor antagonists due to incomplete prevention of reactivation of latent infection. Arthritis Rheum 2007;57:756-61.

2. Sichletidis L, Settas L, Spyratos D, et al. Tuberculosis in patients receiving anti-TNF agents despite chemoprophylaxis. Int J Tuberc Lung Dis 2006;10:1127-32.

3. Tahaoglu K, Torun T, Sevim T, et al. The treatment of multidrug-resistant tuberculosis in Turkey. N Engl J Med 2001;345:170-4.

\section{Authors' response}

Bourikas et al describe a case of disseminated tuberculosis (TB) in a patient with Crohn's disease given 6.5 months isoniazid and infliximab. Rampton's paper ${ }^{1}$ stated that "although the incidence of infliximabrelated TB may now be falling due to improved risk assessment, chemoprophylaxis, and/or reporting fatigue, complacency is clearly inappropriate" It also summarised and referred to the full text of the British Thoracic Society/British Society of Gastroenterology/British Society of Rheumatology guidelines ${ }^{2}$ published in the same year. Under section 4.6 of the full guidelines, ${ }^{2}$ we wrote "It should be noted 